\title{
Chemical and Phase Characterization of Snail Shell (Archachatina Marginata) as Bio-Waste from South-West in Nigeria for Industrial Applications
}

\author{
Helen Tola Owoyemi ${ }^{1^{*}} \quad$ Akinwumi Gbenga Owoyemi $^{2}$ \\ 1.Department of Mineral and Petroleum Resources Engineering, Federal Polytechnic, Ado-Ekiti \\ 2.Deaprtment of Glass and Ceramic Technology, Federal Polytechnic, Ado-Ekiti
}

\begin{abstract}
This paper aimed at characterizing waste snail shells found in South-West, Nigeria for potential industrial applications. Snail shells which represent the bio-shell waste of snails' remnants from restaurants, eateries or snail sellers constitute a serious degree of environmental threat with little or no economic value; their effective utilization can bring immense economic prosperity. Snail shells were obtained from two selected region of SouthWestern part of Nigeria. The obtained snail sells were thoroughly washed to remove adhered dirt and later dried in an electric powered oven at $110^{\circ} \mathrm{C}$ for $6 \mathrm{~h}$. The dried shells were then crushed and further pulverized to obtain powder snail shells $\left(\mathrm{SS}_{\mathrm{p}}\right)$ and labeled samples $\mathrm{SS}_{\mathrm{p}} \mathrm{A}$ and $\mathrm{SS}_{\mathrm{p}} \mathrm{B}$ respectively. The chemical composition of the samples was determined by Energy dispersive X-ray (SEM/EDX) while the phase constituent was analyzed using $\mathrm{X}$-ray diffractometer. The results showed that $\mathrm{SS}_{\mathrm{p}} \mathrm{A}$ consist mainly calcium (Ca) $83.38 \%$ while sample $\mathrm{SS}_{\mathrm{p}} \mathrm{B}$ contains higher calcium (Ca) content of $85.04 \%$. However, X-ray diffraction (XRD) indicate predominant phase of calcite for the samples. This indicates that the snail shell powder is suitable for industrial applications such as filler in paper and ceramic industry.
\end{abstract}

Keywords: Snail shell; chemical composition; phase constituent; calcite phase.

DOI: $10.7176 / \mathrm{CMR} / 12-6-03$

Publication date:July $31^{\text {st }} 2020$

\section{Introduction}

Land snails are species of snail that live among wet vegetation which are mostly available during rainy seasons and are most active at night [1]. There are different breeds of edible land snails found in Nigeria. The two giant land snails commonly found in Nigeria: Achatina marginata and Achatina achatina. Achatina marginata has no definite shell coloration and it is wider at the posterior end compared to others. The foot is usually dark brown in color. It is the most common breed found in south western Nigeria. Achatinaachatina has a shell with conspicuous zigzag streaks and a narrow apex. The foot is grey in color. Other breeds of snail include; Achatina fulica is of small size and the fleshy part could be whitish or dark brown [2]. Snails find several useful purposes; the edible part of it is used as food whereas its slime is used traditionally as medicine, for the preparation of concoctions for various cases as reduction of labour pains, blood loss during delivery and in the cure of small pox. It also finds relevance in the treatment of anemia, hypertension, high blood pressure and other fat-related ailments [3]. Snail shell on the other hand also has several uses resulting from its hard nature and chemical properties. When the snail grows, its shell (and body) expands only at the aperture margin while the shell thickness and the degree of mineralization increase all the time on the entire shell internal surface, The snail can reach up to $20 \mathrm{~cm}$ in length and up to $12 \mathrm{~cm}$ in diameter. The life span for snails depends on their habitat and the species. Some of them only live for about 5 years however; others in the wild are believed to live at least 25 years old. The life span of snails is decreasing due to humans destroying their habitat and due to pollution [4]. The shells are rich source of calcium and are used as fillers in the ceramic industry, paint, animal feed, construction and paper industry.

Moreover, since the whorls of each shell differ in age, they should also differ in their mineral content, especially in tall-shelled, long-lived species; the literature information on the mineral composition pertains to whole shells but not to individual whorls. Inter-specific differences should also exist. For example, two species of Achatina differ in their haemolymph composition [5] which has a direct bearing on the shell composition.

Snail shell is brownish in colour with dark brown markings. Snail shell is usually very hard and protects the snail from predators, dehydration and physical damage. Locally, snail shell is used in the manufacture of jewels, buttons and collections for arts [6]. Snail shell powder is an important filler in the paper industry. Due to its calcium carbonate and chitin contents, shell powder can be used to increase the mechanical properties of paper. Such properties include: smoothness, abrasion, machine flow ability, brightness, strength and opacity. Shells in powdery form are used in the ceramic industry in the manufacture of breakable plates, pipes and kitchen utensils. Snail shell is a mineral that contains about $98 \%$ of calcium carbonate [7]. It is therefore a biological source of calcium that can be used in animal feeding.

Recent development involves its application in the treatment of water and waste water resulting from its chemical composition. The shell is known to increase the hardness of the product, resistance to weathering and 
strength of the material. The use of snail shell powder in treatment of water has been reported [8]. There is need to characterize snail shell to be able to determine the chemical composition present for its industrial application.

\section{Materials and method}

\subsection{Material}

The main starting material used in this work is snail shell. The snail shells used in this work are of the Archachatina Marginata species and were obtained from Ilaje, Ondo State and Errufun Village, Ado-Ekiti, Ekiti State both from South-Western region in Nigeria. Figure 1 shows a pictorial representation of the snail shell sample. Snail shells collected from Ilaje, Ondo State was labeled Sample SSA while the shells obtained from Ado Ekiti, Ekiti State was labeled sample SSB. The as-received snail shells were initially washed thoroughly with water to remove adhered dirt, and then dried in an electric oven at $110^{\circ} \mathrm{C}$ for $6 \mathrm{~h}$. The dried shells were then crushed using porcelain lined mortar and pestle. The crushed shells were then pulverized using electrically powered laboratory pulverizer to obtain powdered snail shells $\mathrm{SS}_{\mathrm{p}} \mathrm{A}$ and $\mathrm{SS}_{\mathrm{p}} \mathrm{B}$ respectively. The powdered shells were then sieved using a $74 \mu \mathrm{m}$ sieve to obtain a fine powder which was used for this work. Figures $2(a-b)$ show the powdered snail shells respectively.

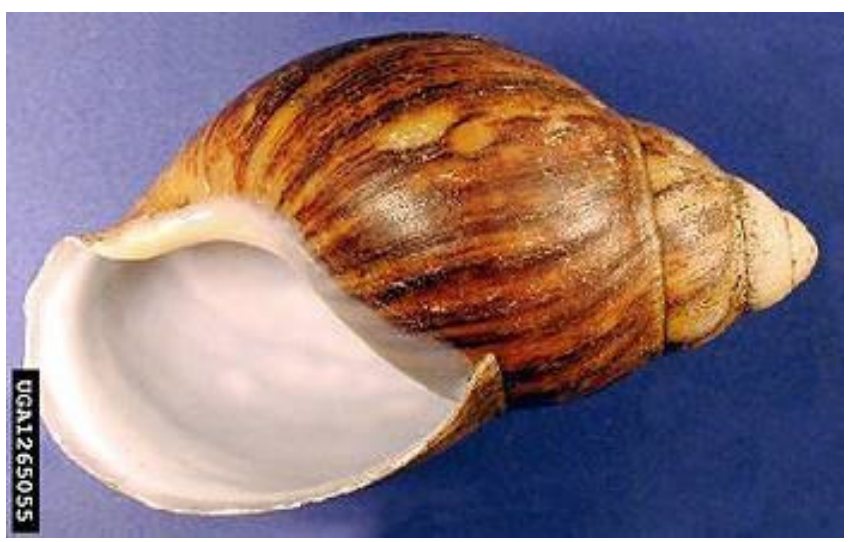

Figure 1. Pictorial representation of snail shell

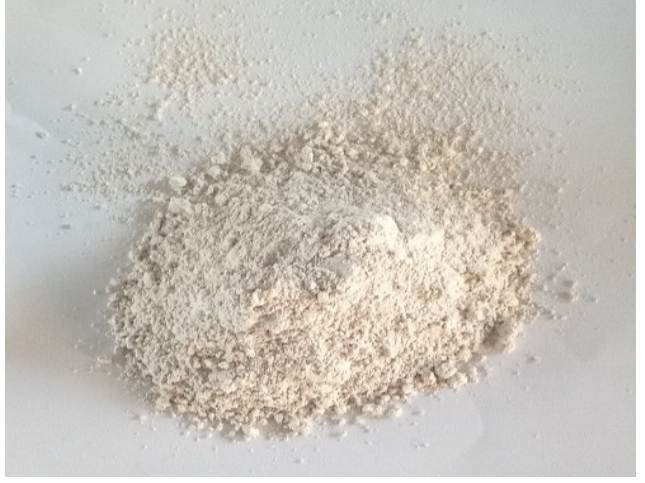

(a)

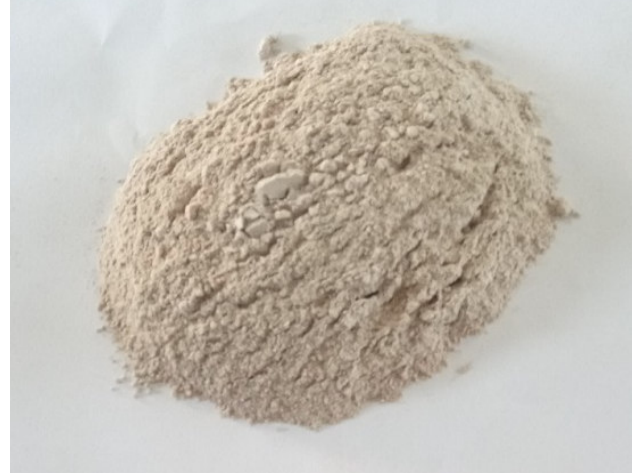

(b)

Figure 2. Pictorial representation of (a) $\mathrm{SS}_{\mathrm{p}} \mathrm{A}(\mathrm{b}) \mathrm{SS}_{\mathrm{p}} \mathrm{B}$

\subsection{Characterization}

The microstructure evaluation was examined using scanning electron microscope with attached energy dispersive spectrometer (SEM/EDS, ASPEX 3020) while the chemical composition was examined by Energy Dispersive Xray fluorescent (XRF-Pananalytical, minipal 4). The XRD analysis of the snail shell powder was carried out using an Empyrean X-ray diffractometer DY 674 (2010) with 40mA, 45VA and 240mm tube current, voltage rating and goniometer radius, respectively

\section{Results and Discussion}

3.1. Microstructure/elemental composition (SEM/EDS)

The results of the microstructure evaluation and the elemental composition of the snail shell powders $\left(\mathrm{SS}_{\mathrm{p}} \mathrm{A}\right.$ and $\mathrm{SS}_{\mathrm{p}} \mathrm{B}$ ) conducted by Scanning electron microscopy with attached Energy dispersive spectroscopy (SEM/EDS) is presented in Figures 3 (a) and (b) respectively. It is observed that both samples displayed similar microstructure revealing a somewhat fibrous morphology. The dark features observed at the surface might be due to the presence 
of carbon strands. This similar feature has been reported by Kolawole et al. [9]. However, the ED spectrum shows that both $\mathrm{SS}_{\mathrm{p}} \mathrm{A}$ and $\mathrm{SS}_{\mathrm{p}} \mathrm{B}$ predominantly contain calcium while others element such as Carbon, Potassium, Oxygen, Magnesium, Sulfur, Sodium, Aluminum and Silicon are in traceable amounts.

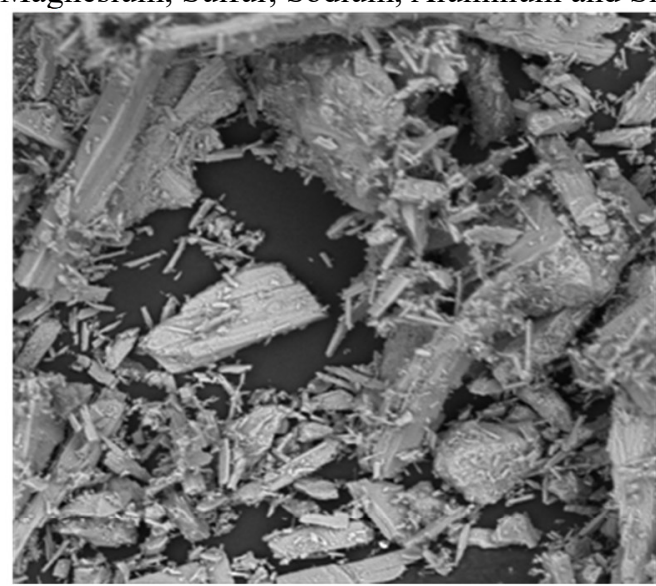

\begin{tabular}{|l|l|l|}
\hline $\begin{array}{l}\text { Element } \\
\text { Symbol }\end{array}$ & $\begin{array}{l}\text { Element } \\
\text { Name }\end{array}$ & $\begin{array}{l}\text { Weight } \\
\text { Conc. }\end{array}$ \\
\hline $\mathrm{Ca}$ & Calcium & 83.38 \\
\hline $\mathrm{O}$ & Oxygen & 0.95 \\
\hline $\mathrm{C}$ & Carbon & 5.67 \\
\hline & Other & 9.58 \\
\hline
\end{tabular}

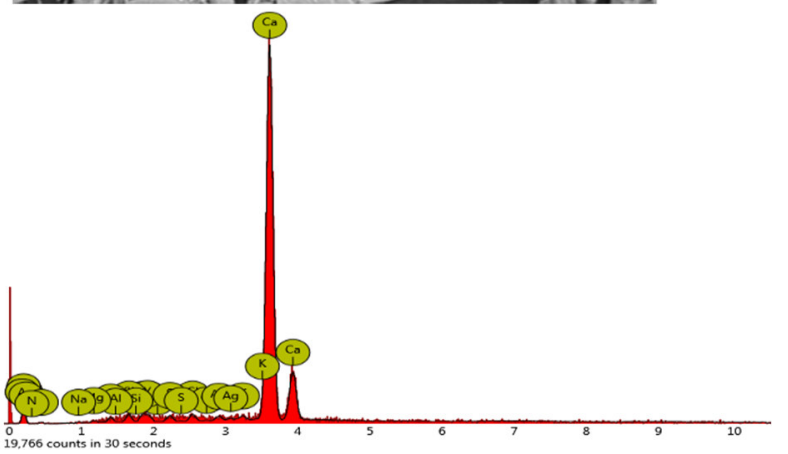

(a)

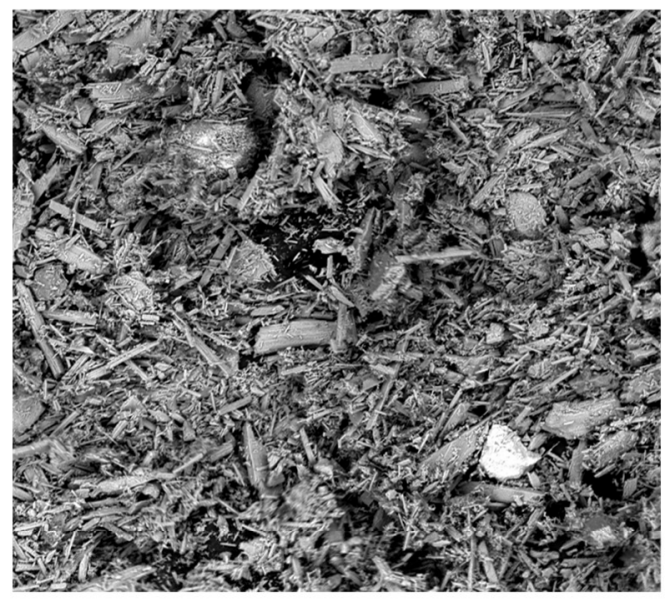

\begin{tabular}{|l|l|l|}
\hline $\begin{array}{l}\text { Element } \\
\text { Symbol }\end{array}$ & $\begin{array}{l}\text { Element } \\
\text { Name }\end{array}$ & $\begin{array}{l}\text { Weight } \\
\text { Conc. }\end{array}$ \\
\hline $\mathrm{Ca}$ & Calcium & 85.04 \\
\hline $\mathrm{O}$ & Oxygen & 0.26 \\
\hline $\mathrm{C}$ & Carbon & 1.96 \\
\hline & Others & 12.74 \\
\hline
\end{tabular}

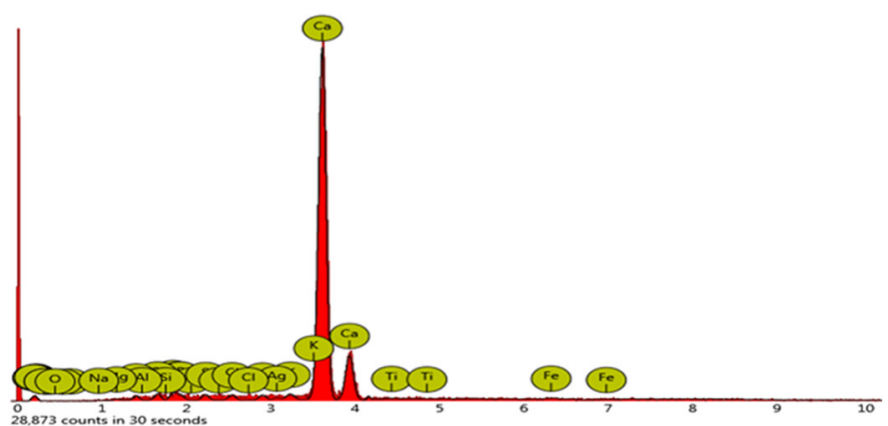

(b)

Figure 3. SEM/EDS of (a) $\mathrm{SS}_{\mathrm{p}} \mathrm{A}$ (b) $\mathrm{SS}_{\mathrm{p}} \mathrm{B}$ 


\subsection{Oxide compositional analysis (EDXRF)}

Table 1 shows the result of the oxide composition of the samples using the Energy Dispersive X-Ray Fluorescence $(\mathrm{XRF})$ analysis while Figures $4(\mathrm{a}-\mathrm{b})$ indicate the EDX spectrum of the samples $\mathrm{SS}_{\mathrm{p}} \mathrm{A}$ and $\mathrm{SS}_{\mathrm{p}} \mathrm{B}$ respectively. The result confirmed the presence of $\mathrm{K}_{2} \mathrm{O}, \mathrm{Fe}_{2} \mathrm{O}_{3}, \mathrm{CaO}, \mathrm{P}_{2} \mathrm{O}_{5}, \mathrm{Al}_{2} \mathrm{O}_{3}, \mathrm{ZnO}$ and $\mathrm{SrO}$ with $\mathrm{CaO}, \mathrm{Cr}_{2} \mathrm{O}_{3}, \mathrm{TiO}_{2}$ and $\mathrm{MnO}$ as the major constituents of the snail shell sample. This however confirmed the results obtained in Figures 3 $(\mathrm{a}-\mathrm{b})$. It can be observed from Figure $4 \mathrm{a}$ that the concentration of $\mathrm{CaO}$ of Sample $\mathrm{SS}_{\mathrm{p}} \mathrm{A}$ is at its peak $(173730$ $\mathrm{cps} / \mathrm{mA})$ and that of sample $\mathrm{SS}_{\mathrm{p}} \mathrm{B}$ in Figure $4 \mathrm{~b}$ was at the peak $(152962 \mathrm{cps} / \mathrm{mA})$, this was similar to that obtained by previous researchers [10].

Table 1 Oxide Composition of Snail shell particles

\begin{tabular}{clllllllllll}
\hline Oxide & $\mathrm{CaO}$ & $\mathrm{P}_{2} \mathrm{O}_{5}$ & $\mathrm{Na}_{2} \mathrm{O}$ & $\mathrm{K}_{2} \mathrm{O}$ & $\mathrm{MgO}$ & $\mathrm{Al}_{2} \mathrm{O}_{3}$ & $\mathrm{ZnO}$ & $\mathrm{SiO}_{2}$ & $\mathrm{Fe}_{2} \mathrm{O}_{3}$ & $\mathrm{TiO}_{2}$ & $\mathrm{Cr}_{2} \mathrm{O}_{3}$ \\
\hline $\mathrm{SS}_{\mathrm{p}} \mathrm{A}$ & 74.30 & 0.22 & 0.25 & 0.21 & 0.62 & 1.35 & 0.01 & 0.55 & 0.04 & 0.01 & 0.001 \\
& & & & & & & & & & & \\
$\mathrm{SS}_{\mathrm{p}} \mathrm{B}$ & 84.38 & 0.08 & 0.92 & 0.15 & 0.06 & 1.22 & 0.01 & 0.69 & 0.07 & 0.01 & 0.000 \\
\hline
\end{tabular}

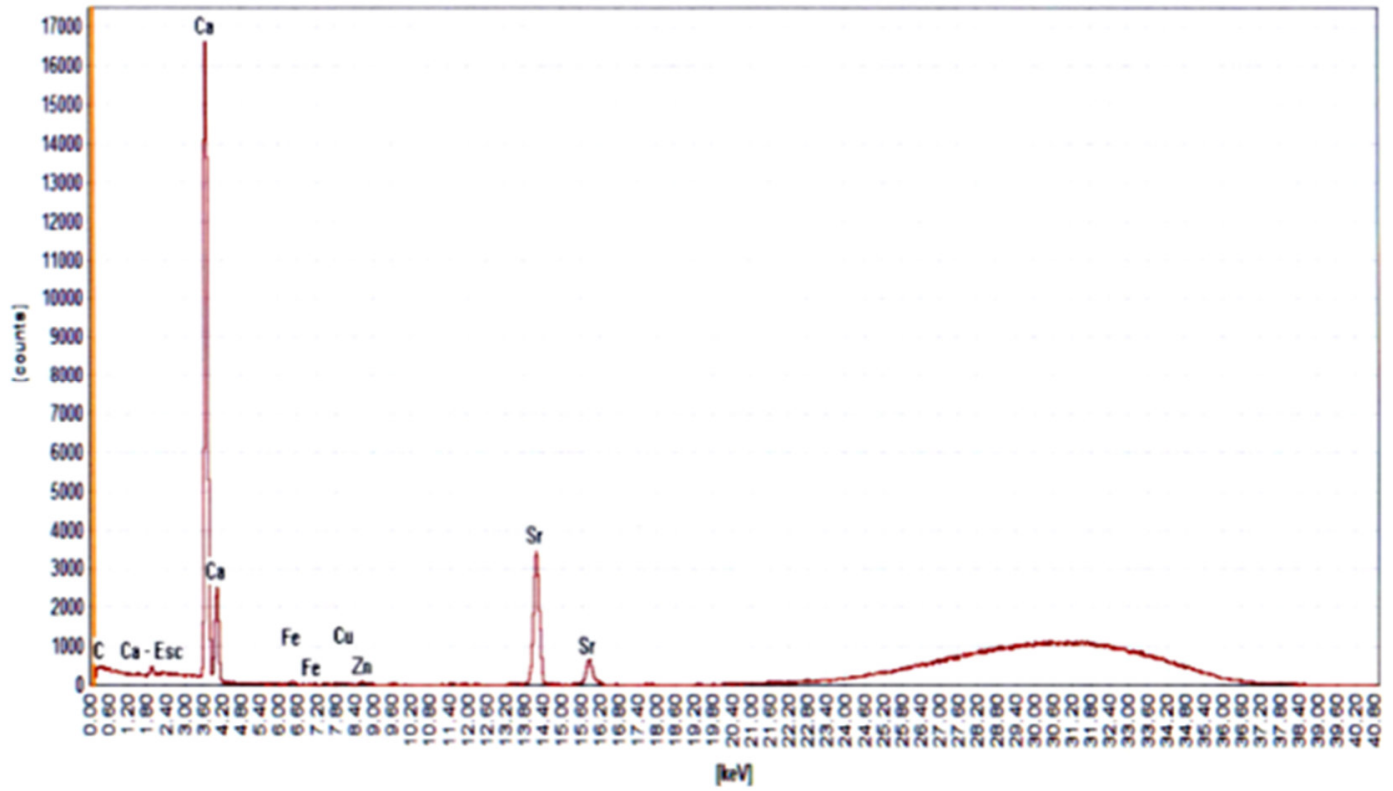

(a)

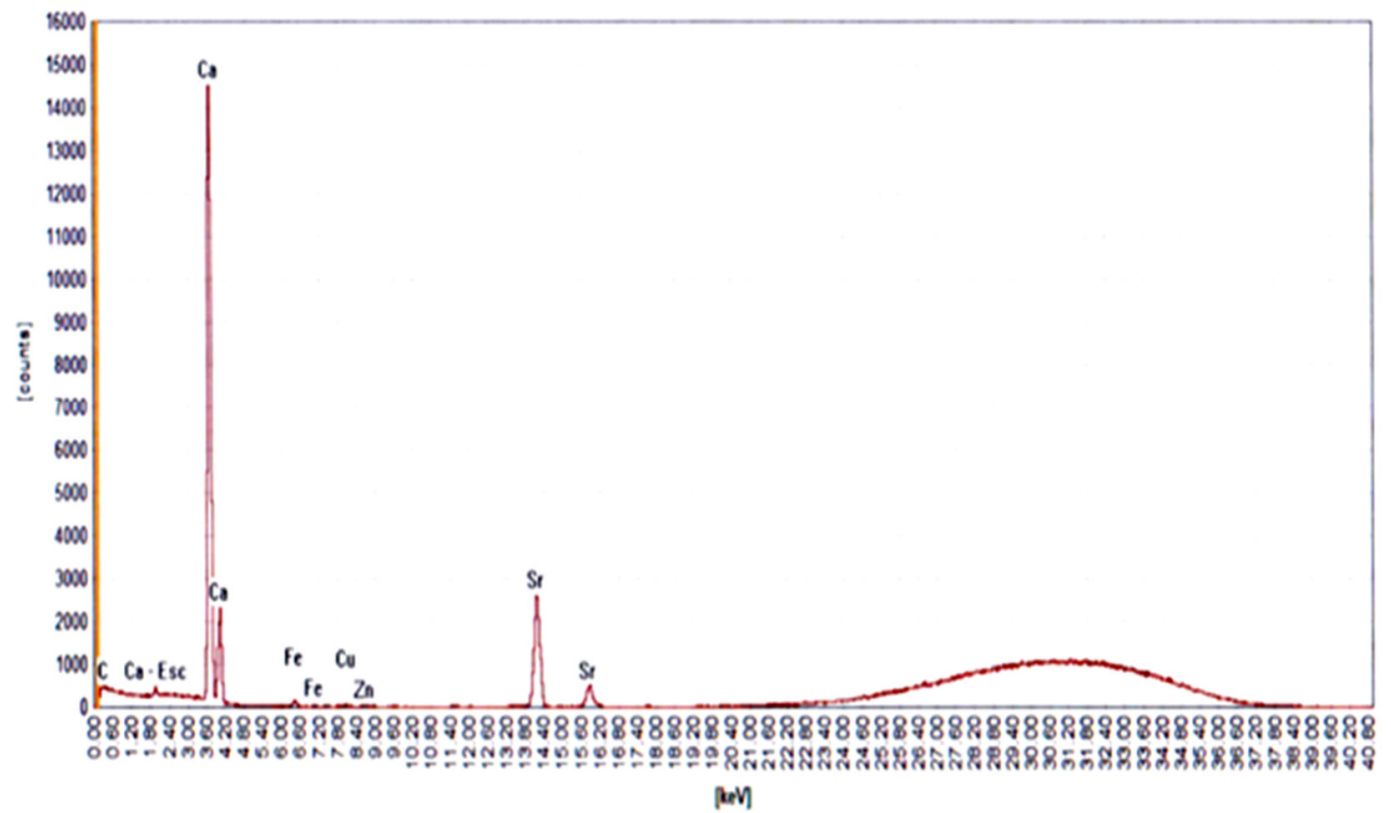

(b)

Figure 4. EDX Spectrum of (a) $\mathrm{SS}_{\mathrm{p}} \mathrm{A}$ (b) $\mathrm{SS}_{\mathrm{p}} \mathrm{B}$ 


\subsection{Phase composition}

The results of the phase composition investigated by X-ray diffractometer is presented in Figures 5 (a) and (b). The XRD pattern obtained revealed that the diffraction peaks are $26.8660^{\circ}$ and $36.6856^{\circ}$ and their inter-planar distance is $3.31585 \AA$ and $2.44974 \AA$ with a relative intensity of the X-ray scattering of 100.00 and 100.00 . The phases at these peaks are aragonite and calcite with a score of 27 and 25, respectively. The presence of these minerals in the shell forms the bases of the hard nature of the shells.

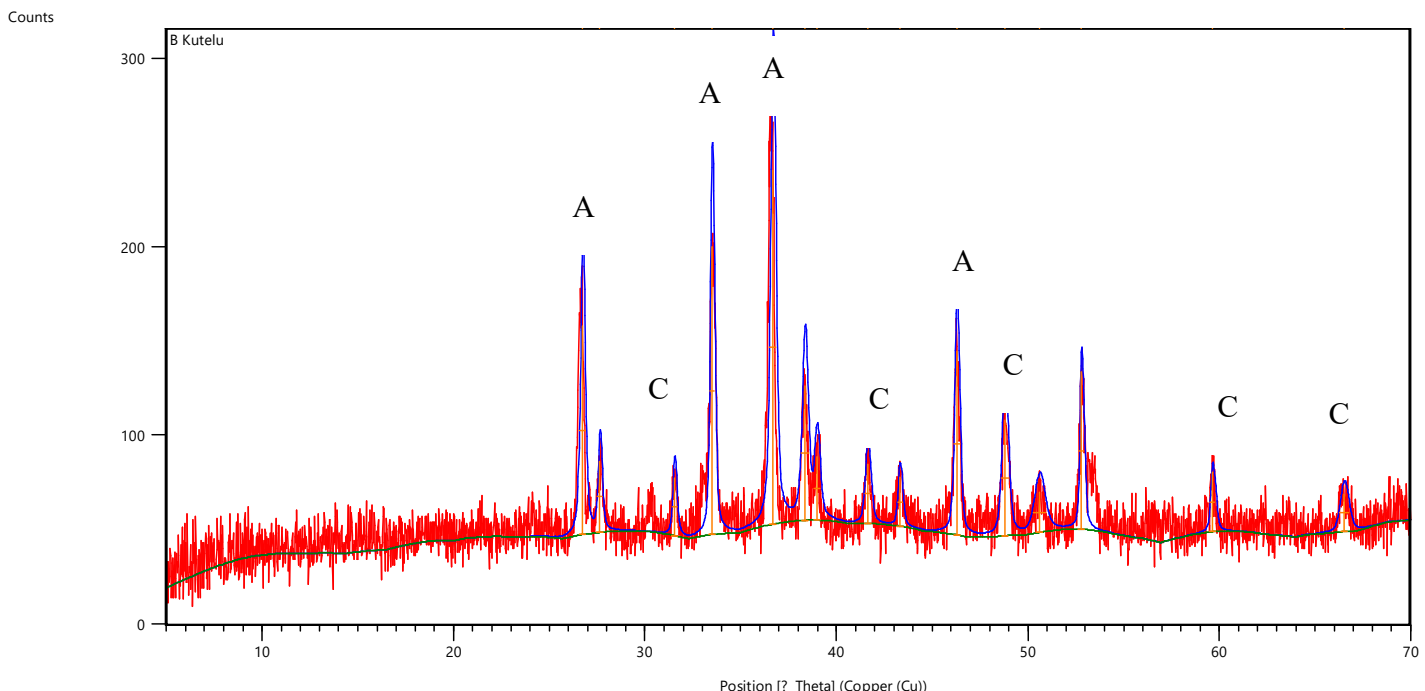

(a)

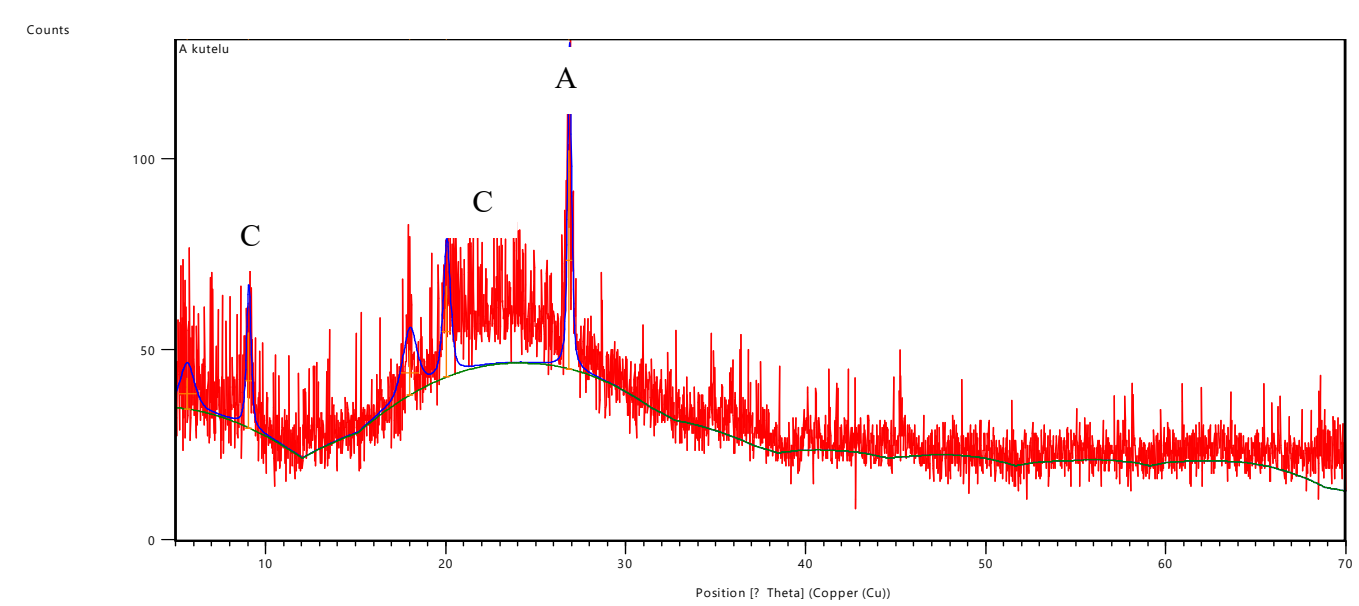

(b)

A - aragonite, $\mathrm{C}$ - calcite

Figure 5. XRD pattern of (a) $\mathrm{SS}_{\mathrm{p}} \mathrm{A}$ (b) $\mathrm{SS}_{\mathrm{p}} \mathrm{B}$

\section{Conclusion}

The concentration of $\mathrm{CaO}$ in both samples was at the peak $83 \%$ and $81 \%$ respectively, it was also observed that the concentrations of the metals were in decreasing order: $\mathrm{Ca}>\mathrm{K}>\mathrm{Na}>\mathrm{Mg}>\mathrm{Fe}>\mathrm{Zn}$ in both samples. Some useful elements present in snail shell powder shows that the snails shell powder can be used in industries as fillers, an additive in the production of toothpaste, mineral supplement as well as cement, mortar, glass, plastics, acetylene gas, insecticide and water treatment agents due to the presence of calcium oxide.

\section{Reference}

[1] Egbon, E., Jatto, E., Asia, I. and Ize, I. O. (2006). Proximate and mineral composition of Mukana Pruriens. Chem. Tech. Journal, 3, pp.640-642.

[2] Aluko F, and Adisa A. (2014) Qualitative characteristics and Suture measurements of two breeds of snail reared in Nigeria. American Journal of Experimental Agriculture. (4): pp.1492.

[3] Wosu, A.A and Oseni, O.A (2004). National value and functional properties of pond snails (lymnaeastagnalis). 
Proceeding of the International Conference on Science and National Development, 2004. Pp. 90-93

[4] Barker G. M. (ed.) (2001). The biology of terrestrial molluscs. CAB International, Hamilton, New Zealand. http://dx.doi.org/10.1079/9780851993188.0000

[5] Idowu A. B., Somide O. M., and Ademolu K. O. (2008). Comparative analysis of the chemical composition of the haemolyph, flesh and the microflora content of the guts of some African land snails in Abeokuta Nigeria. Tropical Veterinarian (26): pp. 20-29

[6] Jatto, O. E. (2010); Proximate and mineral composition of different species of snail shell. Pacific Journal of Science and Technology, 11(1), pp. 416-419.

[7] Cobbinah J R, Vink A and Onwuka B (2008); Snail farming: Production, Processing and Marketing. AgrodokSeries No. 47, Agromisa Foundation, CTA, Wageningen, pp.84

[8] Oghenevweta J, Aigbodion V, Nyior G and Asuke F. (2016) Mechanical properties and microstructural analysis of $\mathrm{Al}-\mathrm{Si}-\mathrm{Mg} /$ carbonized maize stalk waste particulate composites. Journal of King Saud UniversityEngineering Sciences. (28) pp.222-9.

[9] Kolawole, M.Y., Aweda, J.O., Abdulkareem, S. (2017). Archachatina marginata bio-shells as reinforcement material in metal matrix composites. International Journal of Automotive and Mechanical Engineering. Volume 14, Issue 1 pp. 4068-4079

[10] Atuanya, C.U., Aigbodion, V.S., Obiorah, S.O., Kchaou, M., and Elleuch, R. (2016). Emperical model for estimating the mechanical and morphological properties of recycled low density polyethylene/snail shell biocomposites. Journal of the Association of Arab Universities for Basic and Applied Sciences. 2(1), pp. 4552 . 